\title{
The Role of Hand, Eye, and Ear Lateralization in the Sense of
}

\section{Rhythm of the Athletes}

\author{
Süleyman Erim Erhan ${ }^{1}$, Zinnur Gerek $^{1}$, Deniz Bedir ${ }^{1}$ \\ ${ }^{1}$ Faculty of Sport Sciences, Ataturk University, Erzurum, Turkey \\ Correspondence: Süleyman Erim Erhan, Faculty of Sport Sciences, Ataturk University, Erzurum, Turkey.
}

Received: May 15, 2018

doi:10.11114/jets.v6i4a.3369

Accepted: June 13, 2018

Online Published: June 15, 2018

URL: https://doi.org/10.11114/jets.v6i4a.3369

\begin{abstract}
This study was carried out to investigate the relationship among the hand, eye, and ear lateralizations and the sense of rhythm of the athletes randomly selected from different sport branches.

A total of 115 elite athletes including 72 males $(62.6 \%)$ and 43 females (37.4\%) whose mean age was $22.3 \pm 2.4$ years and who receive training at different departments of the Faculty of Sports Sciences, Ataturk University were included in the study. Hand preference was assessed based on the Geschwind score by applying Edinburgh Inventory test. The dominant eye was tested by the Dolman Method (hole-in-the-card test). Hearing durations were measured using $128 \mathrm{~Hz}$ diapason and digital chronometer. The rhythm perception and application skills were assessed considering the rhythmic answers given practically to the rhythm patterns previously prepared by the researcher.

As for the handedness of the athletes, 16.5\% of them were left-handed $(n=19), 7.8 \%(n=9)$ were two-handed, and $75.7 \%$ $(\mathrm{n}=87)$ were right-handed. While $18.3 \%(\mathrm{n}=21)$ had good hearing durations with left ear, and $13.9 \%(\mathrm{n}=16)$ had good hearing durations with right ear, $67.8 \%(n=78)$ had very close hearing durations with two ears. While left eye of $41.7 \%$ $(\mathrm{n}=48)$ was dominant, the right eye of $58.3 \%(\mathrm{n}=67)$ was dominant. According to the rhythm perception and application test results, $46.1 \%$ of the athletes were weak $(n=53), 30.4 \%$ at the midlevel $(n=35), 13.9 \%(n=16)$ good, and 9.6\% $(n=11)$ at very good level.

No significant relationship was found between the eye and ear lateralization of the athletes and their rhythm perception and application skills; however, it was found that the sense of rhythm of the left-handed individuals was better than the right-handed ones with respect to the handedness.
\end{abstract}

Keywords: athletes, rhythm, lateralization

\section{Introduction}

Sports are such practices that are intended for ensuring and developing that an individual can realize his/her self, body, capacity of using his/her body, and movement factors within his/her physical environment. According to Meinel and Schnabel, the movement scheme of the athlete consists of mutual interaction of some of aspects of human. The complex structure of the movement has been basically studied under the main headings of rhythm and transfer of the movement. In learning the movements, these two factors prominently stand out (Meinel \& Schnabel, 2007).

Each person is always confined to the same body since the moment they were born. Different types of sports are intended for exercising different muscle groups in the athlete's body. The movements of the human body are complex events that the nervous system and request for movement create within some series of rules (Gerek, 2015). Among these complex events, the cerebral lateralization and the rhythm of movement are determinative because our right hand is managed by the left brain, and our left hand is managed by the right brain. Hence, the left brain is dominant in right-handed, while the right brain is dominant in left-handed. Therefore, it can be easily said that the superior skill of the left hand to the right hand in left-handed relies on the right brain, and the superior skill of the right hand to the left hand in right-handed relies on the left-brain (Özdemir \& Soysal, 2004).

The hand preferred to be used at the moment of a work is defined as the dominant hand, as it is functionally more dominant than the other hand. The handedness gives significant hints about the organization of the high mental 
functions in the brain of the person. In other words, it provides us to predict in this way (Gündogan, 2005).

Subjects can accommodate to rhythms they sense within physiological rules and movement skills. Each regular movement and each action develops in accordance with the speed (pace) and rhythm because each regular movement made by the human has also a speed-rhythm relation based on the rhythm of the triggering internal action. The skillful movement emerges with the timely arrival of the signals coming from the nervous system to the muscles required to be contracted. This relationship emerging between the brain, nervous system, and muscles also ensures that such aspects as muscular force, flexibility, joint mobility, strength, and agility will develop in parallel with the sense of rhythm.

Cerebral lateralization denotes the morphological and functional differences between the two hemispheres of the brain (McManus, 2013). In the majority of the people, the motor control spheres, rear (sensorial) speech center (Wernicke space) and front (motor) speech center (Broca space) are usually better developed in a cerebral hemisphere than the other hemisphere. This better developed hemisphere is called "dominant hemisphere". Approximately 95\% of the people have a dominant left hemisphere (Gundogan, Yazıcı, Ogus \& Simsek, 2007).

The handedness is guiding in determining the dominant hemisphere. As, however, the handedness is affected by the training, it has also been suggested that it cannot represent the natural functional asymmetry of the brain, as an acquired preference (Gündogan, 2005). In addition, McManus et al. (2013) have reported that the eye dominancy is not affected by the education at all, and it truly reflects the functional asymmetry of the brain. It is reported that there is usually a harmony between the handedness and the dominant eye. Accordingly, it is widely accepted that the right eye is dominant in those who use their right hand, and the left eye is dominant in those who use their left hand (McManus, 2013). However, there is not always a harmony between the handedness and the dominant eye.

Although it is known that the musical perception emerges in the right hemisphere, it could not be found where the music center is located in the brain. The right lobe of the brain is important to perceive the certain aspects of the melody such as a sound volume as well as harmony, volume and rhythm. To perceive the whole rhythm, both the right and left lobes of the brain are required. The frontal cortex of the brain related to the memory takes part in perceiving the rhythm and melody (Yayla, 2003).

The higher rates of left-handedness was reported among top athletes in the different sports such as baseball (McLean \& Ciurczak, 1982), tennis (Azemar, Ripoll, Simonet \& Stein, 1983; Holtzen, 2000), fencing (Bisiacchi, Ripoll, Stein, Simonet \& Azemar, 1985), cricket (Wood, 1989), boxing (Gursoy, 2008), and wrestling (Ziyagil, Gursoy, Dane \& Ramazan, 2010). Two different opinions were suggested: (1) Left-handers might have an innate neurologic advantage over right-handers, possibly due to superior spatio-motor skills (Annett, 1985; Geschwind \& Galaburda, 1985; Geschwind \& Behan, 1982; Dane \& Erzurumluoglu, 2003) and (2) The increased proportions of left-handers in various sports are due to the nature of the games themselves, and not to neurological advantages related to handedness (Bisiacchi, Ripoll, Stein, Simonet \& Azemar, 1985). Brooks, et al. (2004) analyzed the batting records from the 2003 cricket World Cup and found more success among left-handed than right-handed batsmen; the most successful teams had almost $50 \%$ lefthanded batsmen claimed that an excess of left-handers in sports is due to strategic advantage that is handedness-related: lefthanders' actions and body language differ from right-handers, and since they are less prevalent, other athletes may have less experience defending against those actions.

Therefore, the aim of the present study was to evaluate the relationships of sense of rhythm with handedness, earedness, and eyedness in male and female student athletes from different sports.

\section{Method}

\subsection{Research Model}

This research is a cross-sectional, descriptive and analytic study carried out for investigating the relationships between the handedness, hearing durations, and the eye dominance, and the rhythm perception and application skills of the male and female elite athletes who study at the Faculty of Sports Sciences, Ataturk University. The main result criterion of the study was "rhythm perception and application skill." As the independent variable; age, gender, sports branch, and hand, eye and ear lateralization were investigated.

\subsection{Study Group}

The study was carried out after getting the approval as registered under no. 70400699/10.01-68 from the Ethics Committee of the Faculty of Sports Sciences, Ataturk University. One hundred and twenty-five students (75 males and 50 females) who are competitors and have already had a national/international degree, and studied at the Faculty of Sports Sciences, Ataturk University during the academic year of 2016-2017 were invited to the study.

\subsection{Sample Size Calculation}

Samples size calculation was based on the "rhythm perception and application skills score". One hundred and eleven 
participants were needed to compare the three groups (right, both right and left, and left handed participants) using one-way ANOVA with alpha error $=0.05$, effect size $=0.3$, and power $=80 \%$.

\subsection{Sampling}

All the participants underwent a medical examination. There was no student who declined to participate in the study. The subjects who had previously undergone an eye operation or had any pathology decreasing their visual acuity as well as subjects with the external auditory canal being not clear and with hearing problems (a total of 10 people) were excluded from the study.

\subsection{Collection of the Data}

In this study, Edinburgh Inventory Test was applied, and the right hand/left handedness was assessed according to Geschwind score. The dominant eye was determined using Dolman Method (hole-in-the-card test). Hearing durations were measured using $128 \mathrm{~Hz}$ diapason and digital chronometer. Rhythm perception and application skills were assessed considering the rhythmic answers practically given to the rhythm patterns previously prepared by the researcher.

\subsection{Personal Data Form}

The personal data form consisting of five questions was used to determine the personal aspects of the athletes (gender, age, length, weight, and sports branch).

\subsection{Course of Study}

The eyes and ears of the subjects who participated in the research were examined by a specialist physician before the study. As a result of the examination, those with any hearing problems, those with external auditory canal being not clear, and the subjects who had previously undergone an eye operation or had any pathology affecting their visual acuity were not included in the study ( $\mathrm{n}=10$ people). The Edinburgh Inventory (handedness) test, Dolman Method (hole-in-the-card test) dominant eye test, hearing durations test developed by Dane and Bayirli (Dane \& Bayirli, 1998), and the rhythm perception and application test developed by the researcher were respectively applied to the athletes. All the tests were conducted at the Physiology Laboratory of the Faculty of Sports Sciences between 12:00 and 15:00. It took approximately 25 minutes to collect the research data from a single participant.

\subsection{Handedness Test}

Edinburg Inventory (Oldfield) handedness test was applied (Dane \& Erzurumluoglu, 2003). The hand which writes, draws, and grabs the scissors, toothbrush, spoon, and hammer, and grabs the matchstick while lighting the fire, and grabs the lid while unpacking the box was determined during the test. The findings were noted down on the data collection form. The answers were assessed between +100 and -100 according to the Geschwind score. The questions were rated respectively as $-10,-5,0,+5$, and +10 score. Accordingly, $-100 /-20$ was accepted as left-handed, $-20 /+20$ two-handed, and $+20 /+100$ right-handed.

\subsection{Hearing Duration Test}

The hearing durations of the athletes were determined for the first time by the method used by Dane and Bayirli (Oldfield, 1971). To this end, a $128 \mathrm{~Hz}$ diapason and digital chronometer were used. After a pulse of fixed power was given through an electronic circuit to the diapason on the device as designed by the above-mentioned authors, the diapason was kept $1 \mathrm{~cm}$ away from the ear as with the Rinne test, and it was ensured that the chronometer was started at the same time when a pulse is given to the diapason through the electronic circuit of the device. An electric button was given to the hand of the subject, and the subject was asked for pushing this button at the time when the vibrations of the diapason ended, (when the vibrations were not heard any more) and stopping the chronometer. The ear dominancy was determined in accordance with the difference in hearing duration between the two ears. The average standard deviation range was determined as \pm 1 standard deviation; and an average -1 standard deviation and below was classified as left and an average +1 standard deviation and above was classified as right. Those between \pm 1 standard deviation were accepted as equal.

\subsection{Eye Dominancy (Dominant Eye) Test}

The dominant eye was determined using Dolman method (hole-in-the-card test) (Yayla, 2003). 10x15 cm card, which consists of "CV" letter, was previously located on the wall right against the subject so that it will be at the eye level of the subject. The subjects were asked for sitting with arms being stretched and located in parallel to the body during the test. A $25 \times 15 \mathrm{~cm}$ card with a space in the middle of with $3 \mathrm{~cm}$ diameter was prepared. The subject was asked for holding this card so that they can bring the "CV" letters on the wall into the middle of this space. Then they were also asked for bringing the card closer to their face so that they will not cause the letters to get out of the image, and it was tested whether they can see the letters by closing their right and left eyes, respectively. If the letters are still visible, when the left eye is closed, the right eye was registered as dominant, and if the letters are still visible, when the right 
eye is closed, the left eye was registered as dominant. The subjects were asked for repeating for several times in terms of harmony and accuracy.

\subsection{Rhythm Perception and Application Test}

A "rhythm perception and application test" was prepared by the researcher to measure the sense of rhythm of the athletes. The test was created with 2, 4, 5 and 6 timed rhythms. Five specialists in this field reviewed the test prepared. The construct validity of the test was enabled in accordance with the expert opinions. The reliability of the test was assessed using the Cronbach alpha coefficient and was found to be 0.748 . The tests were conducted in a silent environment and at the laboratory by the researcher. For each test, individual test forms were drawn up for the subjects. The answers were ticked on the form, and assessed through the scoring table. The rhythmic patterns were ranged from the simplest to the hardest one in the test consisting of four questions (Appendix 1).

\subsection{Statistical Analysis}

All the analyses were conducted using the SPSS 20.0 software package. In the descriptive statistics, mean \pm standard deviation was given for the numerical variables, and $\mathrm{n}$ and percentage were given for the categorical variables. One-way ANOVA for comparative analyses as well as the $t$ test for independent groups, and the test for dependent groups were used. The statistical significant level was considered as $\mathrm{p}<0.05$.

\section{Results}

Of the athletes who participated in the study, $62.6 \%(n=72)$ were males, and $37.4 \%(n=43)$ were females. Their average age was $22.3 \pm 2.4$ years, and their distributions based on their sports branches were determined as $13.0 \%$ in skiing $(\mathrm{n}=15), 13.0 \%$ in football $(\mathrm{n}=15), 13.0 \%$ in basketball $(\mathrm{n}=15), 10.4 \%$ in handball $(\mathrm{n}=12), 9.6 \%$ in volleyball $(\mathrm{n}=11), 8.8 \%$ in wrestling $(\mathrm{n}=10), 7.0 \%$ in outdoor sports $(\mathrm{n}=8), 14.8 \%$ in martial arts, and $10.4 \%$ in athletics $(\mathrm{n}=12)$.

\subsection{Hand, Eye, and Ear Lateralization Results of the Athletes}

With respect to handedness, $16.5 \%$ of the athletes were left-handed ( $\mathrm{n}=19), 7.8 \%$ two-handed $(\mathrm{n}=9)$, and $75.7 \%$ right-handed ( $\mathrm{n}=87)$. For the eye dominance, $41.7 \%$ had their left eye dominant $(\mathrm{n}=48)$, and $58.3 \%$ had their right eye dominant ( $\mathrm{n}=67)$. With respect to hearing durations, $67.8 \%(\mathrm{n}=78)$ of the athletes had equal hearing durations in both of their ears within the average \pm 1 deviation range. In addition, the left ear presented longer hearing durations at average -1 standard deviation and below values in $18.3 \%(\mathrm{n}=21)$ of them, and the right ear presented longer hearing durations at average +1 standard deviation and above values in $13.9 \%(n=16)$ of them (Table 1$)$.

Table 1. Hand, eye, and ear lateralization results of the athletes

\begin{tabular}{|c|c|c|c|c|}
\hline Variety & Organ & Frequency & Percent & Valid Percent \\
\hline \multirow{3}{*}{ Hand Choice } & Left & 19 & 16.5 & 16.5 \\
\hline & Both right and left & 9 & 7.8 & 7.8 \\
\hline & Right & 87 & 75.7 & 75.7 \\
\hline \multirow{3}{*}{ Hearing Durations } & Left & 21 & 18.3 & 18.3 \\
\hline & Equal & 78 & 67.8 & 67.8 \\
\hline & Right & 16 & 13.9 & 13.9 \\
\hline \multirow{2}{*}{ Dominant Eye } & Right eye dominant & 67 & 58.3 & 58.3 \\
\hline & Left eye dominant & 48 & 41.7 & 41.7 \\
\hline Total & & 115 & 100.0 & 100.0 \\
\hline
\end{tabular}

Discription: Place table caption in front of table body and description below the table body. Avoid vertical rules. Be sparing in the use of tables and ensure that the data presented in tables do not duplicate results described elsewhere in the article. 
Table 2. Distribution of the rhythm perception and application skills based on the sports branches

\begin{tabular}{lc}
\hline Discipline & Rhythm Perception Score (mean \pm SD) \\
\hline Outdoor Sports & $14.63 \pm 11.224$ \\
Combat Sports & $13.71 \pm 8.809$ \\
Basketball & $13.07 \pm 7.704$ \\
Football & $10.87 \pm 7.708$ \\
Handball & $10.83 \pm 8.494$ \\
Volleyball & $10.36 \pm 7.187$ \\
Wrestling & $6.80 \pm 4.104$ \\
Ski & $6.80 \pm 6.259$ \\
Athletics & $6.50 \pm 6.667$ \\
\hline
\end{tabular}

Comparison of the hand, eye, and ear lateralization of the athletes with rhythm perception and application skills

The relationships between the handedness, eye dominancy, and hearing durations and rhythm perception and application skills of the athletes participating in the study were evaluated using one-way ANOVA and test for independent groups. While there was not found any significant difference between the hearing durations and eye dominancy, there was a significant difference in terms of handedness. Accordingly, the values of the left-handed ones were better than the right-handed ones (Table 3).

Table 3. Comparison of the hand, eye, and ear lateralization of the athletes with rhythm perception and application skills

\begin{tabular}{lcc}
\hline Organs & $\begin{array}{c}\text { Rhythm Perception Score } \\
(\text { mean } \pm \text { SD })\end{array}$ & Sig. \\
\hline
\end{tabular}

Hand Dominancy

Left $(n=19 ; 16.5 \%)$

$18.11 \pm 9.42$

Both Right and Left ( $\mathrm{n}=9 ; 7.8 \%)$

$9.88 \pm 4.28$

$F=12.797 ; p<0.001$

Right ( $=87 ; 75.7 \%)$

$8.83 \pm 6.93$

Ear Dominancy

Left $(n=21 ; 18.3 \%)$

$11.10 \pm 7.88$

Both Right and Left $(\mathrm{n}=78 ; 67.8 \%)$

$9.51 \pm 7.58$

$\mathrm{F}=2.367 ; \mathrm{p}=0.098$

Right ( $\mathrm{n}=16 ; 13.9 \%)$

$14.13 \pm 9.18$

\section{Eye Dominancy}

Left Eye Dominant ( $\mathrm{n}=48 ; 41.7 \%$ )

Right Eye Dominant ( $\mathrm{n}=67 ; 58.3 \%)$

$\begin{array}{ll}11.40 \pm 8.98 & \mathrm{t}=1.086 \\ 9.76 \pm 7.13 & \mathrm{p}=0.280\end{array}$

\section{Discussion}

According to the results of this study, it is possible to say that there is an indirect, obvious but weak relationship between the hearing durations and eye dominancy and the sense of rhythm of the athletes. However, it is remarkable that there is a significant difference in favor of left-handed between the handedness and the sense of rhythm. It can be concluded that the left-handers had superiority over the right-handers for the sense of rhythm. It can be claimed that the higher prosperity of left-handers in sport can be due to their higher sense of rhythm compared to the right-handers. This study has proposed that the higher sense of rhythm of left-handers may be due to an intrinsic neurological advantage.

In our study, the left-handedness was found to be $16.5 \%$, the right-handedness $75.7 \%$ and both-handedness $7.8 \%$. For the eye dominancy results, the right eye was dominant in $58.3 \%$, and the left-eye was dominant in $41.7 \%$. It was clearly seen that the right hand and the right eye were dominant in the study population. The results corresponded to the findings in the literature (Oldfield, 1971; Baykal, Dane, Akar, Colak \& Pence, 1995). For ear dominancy, it did not create an opinion about the dominant ear that the hearing durations of both ears showed closer results with a percentage of $67.8 \%$. 
According to Geschwind and Behan, testosterone puts the left brain under pressure, and this causes left-handedness. However, it has also been stated that genetic factors may also affect this condition (Annett, 1985). McManus points out that the left-handed are historically and usually the individuals with intelligence above the average (McManus, 2013). In addition, it is thought that the ambidexterity and the left-handedness are supported by some environmental reasons, and that such kind of dominance provides important advantages especially for basketball and handball players, boxers and wrestlers, sculptors, surgeons, and instrumentalists (Uzun \& Alkan, 2002).

It is known that the right hemisphere is dominant in mathematics, geometry, and spatial fields, and left hemisphere has a dominant function in verbal fields as addressing, literature, and poem in learning and developing connected behaviors (Gündogan, 2005). Tan has found that the motor learning ability of the right hand in left-handed war related to the nonverbal intelligence, and the left hand motor learning ability war not related to such type of intelligence (Tan, 2005).

There have been carried out many studies where the handedness and the eye dominancy were examined together for the purpose of determining the functional asymmetry of the brain; however, the relationship between the handedness and dominant eye could not be fully unveiled (Tan, 2005; Aygul, Dane \& Ulvi, 2005). Banks et al. (2004) have reported that if an object is much closer to one of the eyes, the eye closer to that object becomes dominant, even if it is not actually the dominant eye, as the brain sees that object much bigger using that eye (Banks, Ghose \& Hillis, 2004).

The brain structure of the left-handed is different from that of the right-handed with respect to language processing, establishing directional relationships, and processing the feelings. The left-handed are much differently and potentially creative in these respects. In addition, the left-handed population is slightly much skillful compared to the right-handed in respect of music and mathematics (Hardyck \& Petrinovich, 1977). Of course, there are other environmental factors in the asymmetry of the brain. It is obvious that the conscious functions of the brain are not related to the development of both of the brain hemispheres. The brain has two hemispheres but only one conscious. These two brain hemispheres are connected together with the nerve fibers. One instantly learns what the other is doing. Then the communications with the right and left brains are also perfect in those highly intellectual people (Cole, 1955).

In a study carried out between the professional orchestras, it has been shown that a remarkably much population is left-handed. It is so that the left-handed is even much successful with playing such instruments as violins, which appears to be designed for the right-handed. Similarly, it is also seen that the left-handed surpasses in such skills as mathematics (McManus, 2013).

According to a study carried out by Hodges, it has got harder to argue that the functions related to language can be only performed by the participation of the left cerebral hemisphere, or the music can be just played through the participation of the right cerebral hemisphere. According to him, it has been understood that almost all of the mental functions are not a simple process that works with the participation of one or two structures but it realizes with the involvement of a great number of nerve fibers, and the right cerebral hemisphere is involved in the language process, and the left cerebral hemisphere is involved in the process related to the music (Hodges, 2000).

Music was suggested as a therapeutic option in some diseases (Sezer, Sezer \& Toprak, 2015). One can expect that using the findings of this study, new approaches may be developed to link sports, music and rhythm in the medical field.

\section{Conclusion}

Considering the results of our study, the generalization about the left or the right-handedness may not be valid every time. It is a known fact that being either left-handed or right-handed for some sport branches provides some important advantages, while having a good command of both hands also provides important advantages. However, it is known that beginning to be engaged in sports is not a determinative factor in preference of branches, and sometimes in sportive achievement. As a result, given that it is possible to change the hand and foot preferences through training, it can be said that not only the genes but also the environmental factors, training, and experiences are more determinative while developing behaviors specific to that branch.

Being either right-handed or left-handed may sometimes be very effective and determinative. In addition, it is an important issue required to be studied at which level the rhythm aspect is effective in sportive achievement because the movement training constitutes the basis for all the sports branches, and the rhythm constitutes the basis for movement training. The rhythm is the essential factor that enables the regular movements.

It is necessary to have many controlled studies to achieve much clear results in the assessment of all these findings. The studies on this test should be continued considering that rhythm perception and application skill test for movement training is a guiding test to be used both in choosing the talents and in training the athletes. 


\section{References}

Annett, M. (1985). Left, Right, Hand and brain: the right shift theory. London: Erlbaum.

Aygul, R., Dane, S., \& Ulvi, H. (2005). Handedness, Eyedness, and Crossed Hand-Eye Dominance in Male and Female Patients with Migraine with and Without Aura: A Pilot Study. Percept Mot Skills, 100(3 Pt 2), 1137-1142. https://doi.org/10.2466/pms.100.3c.1137-1142

Azemar, G., Ripoll, H., Simonet, P., \& Stein, J. F. (1983). Etude neuropsychologique du omportement des gauchers en escrime. Cinesiologie, 22(3), 7-18.

Banks, M. S., Ghose, T., \& Hillis, J. M. (2004). Relative Image Size, Not Eye Position, Determines Eye Dominance Switches. Vision Res., 44, 229-234. https://doi.org/10.1016/j.visres.2003.09.029

Baykal, O., Dane, S., Akar, S., \& Colak, A. (1995). Pence S, Relationships Between Hand and Preference and Eye Dominance in Normal Human Subjects, TJMS, 24, 95-97.

Bisiacchi, P. S., Ripoll, H., Stein, J. F., Simonet, P., \& Azemar, G. (1985). Left-handedness in fencers: an attentional advantage? Percept Motor Skill, 61(I), 507-513. https://doi.org/10.2466/pms.1985.61.2.507

Cole, J. (1955). Paw Preferences in Cats Related to Hand Preferences in Animals and Men. J. Comp. Physiol., 48, 1239-1247. https://doi.org/10.1037/h0040380

Dane, S. \& Erzurumluoglu, A. (2003). Sex and handedness differences in eye-hand visual reaction times in handball players. Inter. J. Neurosc., 113(7), 923-929. https://doi.org/10.1080/00207450390220367

Dane, S., \& Bayirli, M. (1998). Correlations between Hand Preference and Durations of Hearing for Right and Left Ears in Young Healthy Subjects. Percept Motor Skills, 86, 667-672. https://doi.org/10.2466/pms.1998.86.2.667

Dane, S., Gumustekin, K., Yazici, A. T., \& Baykal, O. (2003). Correlation between Hand Preference and İntraocular Pressure from Right- and Left-Eyes in Right- and Left-Handers. Vision Res., 43, 405-408. https://doi.org/10.1016/S0042-6989(02)00568-0

Gerek, Z. (2015). Rhythm Education in Physical Education Applications, Ataturk University Publications, Erzurum.

Geschwind, N., \& Behan, P. (1982). Left-Handedness: Association with Immune Disease, Migraine and Developmental Learning Disorder. Proc. Natl Acad. Sci., 79, 5097-5100. https://doi.org/10.1073/pnas.79.16.5097

Geschwind, N., \& Galaburda, A. M. (1985). Cerebral Lateralization: Biological Mechanisms, Associations and Pathology: I. A Hypothesis and A Program for Research. Arch Neurol., 42, 428-459. https://doi.org/10.1001/archneur.1985.04060050026008

Gündogan, N. U. (2005). The importance of left and right brain asymmetries (lateralization) for learning and behavior, $J$. Med Sci., 25, 333-336.

Gündoğan, N. U., Yazıcı, A. C., \& Şimşek, A. (2007). Hand Preference Distribution and Functional Lateralization in University Students: Başkent University. General Med. J., 17(2), 99-103.

Gundogan, N. U., Yazıc1, A. C., Ogus, E., \& Simsek, A. (2007). An Original Study for Evaluating the Correlation Between Handedness and Eye Dominance by Different Methods. J. Med. Sci., 27, 155-163.

Gursoy, R. (2009). Effects of left- or right-hand preference on the success of boxers in Turkey. Brit. J. Sports Med., 43, 142-144. https://doi.org/10.1136/bjsm.2007.043547

Hardyck, C., \& Petrinovich, L. F. (1977). Left-Handedness, Psycho Bull, 84(3), 385-404. https://doi.org/10.1037/0033-2909.84.3.385

Hodges, D. A. (2000). A virtual panel of expert researchers, Music Edu. J., 87(2), 40-44. https://doi.org/10.2307/3399647

Holtzen, D. W. (2000). Handedness and professional tennis. Inter J Neurosc.105, 101-119. https://doi.org/10.3109/00207450009003270

McLean, J. M., \& Ciurczak, F. M. (1982). Bimanual dexterity in major league baseball players: A statistical study. New Eng. J. Med., 307, 1278-12. https://doi.org/10.1056/NEJM198211113072025

McManus, C. (2013). Is it True That Left-Handed People are Smarter than Right-Handed People? Sci. Am. Ret., 1(2), 23-28.

Meinel, K., \& Schnabel, G. (2007). Bewegungslehre Sportmotorik: Abriss einer Theorie der sportlichen Motorik unter pädagogischem Aspekt, Berlin. 
Oldfield, R. C. (1971). The Assessment and Analysis of Handedness: The Edinburgh Inventory. Neuropsychologia, 9, 97-113. https://doi.org/10.1016/0028-3932(71)90067-4

Özdemir, B., \& Soysal, Ş. (2009). A Different Perspective on Life: my left hand, Sted., 4, 131-133.

Porac, C., \& Coren, S. (1976). The dominant eye. Psychol. Bull, 83, 880-897. https://doi.org/10.1037/0033-2909.83.5.880

Sezer, B. T., Sezer, O., \& Toprak, D. (2015). What do we Know about Music Therapy? Konuralp Medical J., 7(3), 167-171.

Tan, U. (2005). Motor Stability in Visuomotor Control of Repetitive Hand Movements and its Differential Cerebral Control in Right - Handed Subjects. Int. J. Neurosci, 65,103-116. https://doi.org/10.3109/00207459209003282

Uzun, N., \& Alkan, N. (2002). El, Importance in terms of Dominance and Judicial Document Review. J. Neurology behave, 40(1), 3-9.

Wood, C. J., \& Aggleton, J. P. (1989). Handedness in 'fast ball' sports: Do lefthanders have an innate advantage, Brit. J. Psych., 80(2), 227-240. https://doi.org/10.1111/j.2044-8295.1989.tb02316.x

Yayla, A. (2003). Measurement of musical talent, Gazi University, Institute of Education, Unpublished Phd Thesis. Ankara.

Yıldırım, S., \& Dane, S. (2007).Cerebral Lateralization and Hand Preference. Euras. J. Med., 39.

Ziyagil, M. A., Gursoy, R., Dane, S., \& Ramazan, Y. (2010). Left-Handed Wrestlers Are More Successful. Perceptual Motor Skills, 111, 65-70. https://doi.org/10.2466/04.05.19.25.PMS.111.4.65-70

Appendix A

Rhythm Perception and Application Skills Measure

Scoring of Test Items:

Test 1-

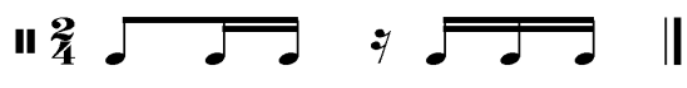

\begin{tabular}{|c|c|c|c|}
\hline 1.TRIA & 2.TRIAI & 3.TRIAI & \multirow{2}{*}{ FAILED } \\
\hline 4 POINTS & 2 POINTS & 1 POINTS & \\
\hline
\end{tabular}

Test 2-

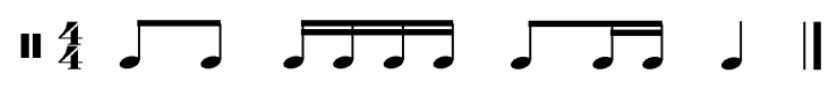

\begin{tabular}{|c|l|l|l|l|l|l|}
\hline \multicolumn{2}{|c|}{ 1. TRIAL } & \multicolumn{2}{|c|}{ 2. TRIAL } & \multicolumn{2}{|c|}{ 3. TRIAL } & \multirow{2}{*}{ FAILED } \\
\hline 6 POINTS & 4 POINTS & 3 POINTS & & \\
\hline
\end{tabular}

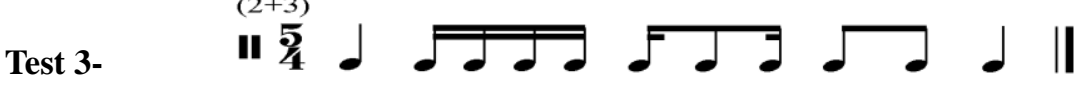

\begin{tabular}{|c|l|l|l|l|l|l|}
\hline \multicolumn{2}{|c|}{ 1. TRIAL } & \multicolumn{2}{c|}{ 2. TRIAL } & \multicolumn{2}{c|}{ 3. TRIAL } & \multirow{2}{*}{ FAILED } \\
\cline { 1 - 3 } 10 POINTS & 8 POINTS & 4 POINTS & & \\
\hline
\end{tabular}

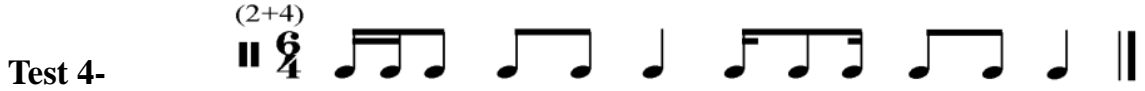

\begin{tabular}{|c|l|l|l|l|l|l|}
\hline \multicolumn{2}{|c|}{ 1. TRIAL } & \multicolumn{2}{c|}{ 2. TRIAL } & \multicolumn{2}{c|}{ 3. TRIAL } & \multirow{2}{*}{ FAILED } \\
\hline 10 POINTS & 8 POINTS & 4 POINTS & \\
\hline
\end{tabular}




\section{Application of the Test:}

-Researcher and subject sit across the table

-Researcher taps the table with the back of the pen he/she is holding and provides applied information on how to conduct the test.

-The subject is asked to hold the pen on the table and to make rhythmic noises like the researcher by tapping on the table with the end of the pen.

-After it is explained how the test will be conducted, the rhythms on the test form shall be inquired by the researcher in an applied manner and the subject will be asked to repeat the sounds he/she hears by tapping on the table.

-Rhythmic pattern will be applied once by the researcher. If the subject responds correctly, the next question is asked. In case of a wrong answer, the subject can try three times. However, each wrong answer will affect the score.

-Answers will be recorded by being marked in the pre-determined field on the test form.

-According to the rhythm perception and application test results, assessment table for feeling rhythms is as the following.

Interpretation of the Test

\section{EVALUATION TABLE}

\begin{tabular}{|c|c|c|c|}
\hline BETWEEN 0 - 7 & BETWEEN 8 - 15 & BETWEEN 16 - 22 & BETWEEN 23 - 30 \\
\hline BAD & NOT GOOD & GOOD & VERY GOOD \\
\hline
\end{tabular}

\section{Copyrights}

Copyright for this article is retained by the author(s), with first publication rights granted to the journal.

This is an open-access article distributed under the terms and conditions of the Creative Commons Attribution license which permits unrestricted use, distribution, and reproduction in any medium, provided the original work is properly cited. 